\title{
Mechanistic Causation and Constraints: Perspectival Parts and Powers, Non-Perspectival Modal Patterns
}

\author{
Jason Winning
}

\begin{abstract}
Any successful account of the metaphysics of mechanistic causation must satisfy at least five key desiderata. In this paper, I lay out these five desiderata and explain why existing accounts of the metaphysics of mechanistic causation fail to satisfy them. I then present an alternative account which does satisfy the five desiderata. According to this alternative account, we must resort to a type of ontological entity that is new to metaphysics, but not to science: constraints. In this paper, I explain how a constraints-based metaphysics fits best with the emerging consensus on the nature of mechanistic explanation.
\end{abstract}

1. Introduction

2. Five Desiderata for an Account of Mechanistic Causation

2.1 The first two desiderata: Intrinsicness and productivity

2.2 The third desideratum: Scientific validity/non-mysteriousness

2.3 The fourth desideratum: Directionality

2.4 The fifth desideratum: Perspectival nature of mechanisms

3. Constraints and Causation

3.1 Multi-Perspectival realism and causal structure

3.2 Causal structure as laws

3.3 Causal structures in analytical mechanics: Constraints

3.4 A metaphysics inspired by analytical mechanics: Constraints as ontologically primitive modal structures

4. Constraints and Mechanistic Causal Powers

4.1 Inter-versus intra-perspectival categories

4.2 Mechanistic causal powers are grounded by constraints

4.3 Intrinsicness and constraints

4.4 Constraints and productiveness

4.5 Constraints and directionality

5. Conclusion 


\section{Introduction}

Mechanistic explanation is ubiquitous in science, and philosophy of science has been making great progress in gaining a realistic understanding of the epistemic practices of scientists. Less progress has been made in understanding the metaphysical implications of these new insights about mechanistic explanation. I argue that this is due to the fact that as a result of the insights gained about mechanistic explanation, there are now at least five key desiderata that must be satisfied by any account of its metaphysical underpinnings, and no extant account has managed to satisfy all five. In this paper, I lay out these five desiderata and explain why existing accounts of the metaphysics of mechanistic causation fail to satisfy them. I then present an alternative account which does satisfy the five desiderata. According to this alternative account, we must resort to a type of ontological entity that is new to metaphysics, but that has been familiar to scientists for two centuries: constraints. In this paper, I explain how a constraints-based metaphysics fits best with the emerging consensus on the nature of mechanistic explanation. ${ }^{1}$

\section{Five Desiderata for an Account of Mechanistic Causation}

The standard scientific realist ontology has it that objects (here conceived broadly enough to include entities such as particles and fields) exist, they have properties, and the universe has laws that determine what happens to these objects and properties over time. Scientists discover these laws and are able to explain observations of objects and properties and how they change (that is, phenomena) by reference to the laws.

Much has been written recently about the fact that, prima facie at least, this picture does not fit the epistemic practices of scientists in a number of domains, for example in biology. Biologists do not generally seek out or refer to laws to explain phenomena (Smart [1963], pp. 50-61; Bechtel and Abrahamsen [2005], p. 422); instead, biological explanations often appeal to mechanisms (Polányi [1958], p. 357; Wimsatt [1976], p. 671). What are the implications of this fact for the scientific realist ontology? One might respond to this fact by denying scientific realism in general, or denying realism about mechanisms in particular. ${ }^{2}$ Perhaps scientific explanations in general, or mechanistic explanations in particular, are not true by virtue of referring to real entities in the first place. Maybe biologists' mechanisms are mere metaphors or useful fictions.

No attempt will be made in this paper to defend any stance on debates between realism and antirealism. Instead, I want to begin by adopting the most straightforward metaphysical

\footnotetext{
${ }^{1}$ I do not discuss it in this paper, but there is arguably a sixth desideratum: the need to account for control relationships in biological mechanisms. To see how the present constraint-based framework rises to this challenge, see (Winning and Bechtel [forthcoming]).

${ }^{2}$ The question of whether or not mechanisms are real is orthogonal to the debate about the metaphysics of explanations, i.e., whether explanations themselves consist of causal structures (the 'ontic view' of explanations) or representations (the 'epistemic view'; see Glennan [2017], Section 8.2 for an excellent overview of this debate).
} 
interpretation of the practice of biologists and granting the New Mechanist view that 'mechanisms are real systems in nature' (Bechtel [2006], p. 33), in order to see what type of view about causation squares best with treating mechanisms as real in some robust sense. What is a scientific realist to conclude from the fact that biology explains in terms of real mechanisms rather than laws? When we look at the reasons why New Mechanists have rejected conventional accounts of causation, ${ }^{3}$ the five desiderata will emerge.

\subsection{The first two desiderata: Intrinsicness and productivity}

One of the themes of the New Mechanist literature is that mechanisms and their components are productive of changes, and that this productive nature is intrinsic to them. A mechanistic explanation does not merely describe occurrent regularities in the way a system changes over time and posit some type of external principle of change, such as laws, for the purpose of assigning responsibility for the production of these changes. Instead, with mechanistic explanation, what is responsible for producing changes lies within the mechanism itself, and the buck stops there. Machamer, Darden, and Craver (henceforth MDC) explain that in this sense, mechanistic explanation implies the rejection of a certain type of Humeanism about causation:

We should not be tempted to follow Hume and later logical empiricists into thinking that the intelligibility of activities (or mechanisms) is reducible to their regularity. [...] Rather, explanation involves revealing the productive relation. ([2000], pp. 21-2)

MDC argue that traditional ontological categories such as that of object, property, or process, which allow us to talk about the intrinsic nature of mechanisms, are not sufficient for characterizing the productive nature of mechanisms, and they argue that we must make room for activities as a category in our ontology:

[...] it is artificial and impoverished to describe mechanisms solely in terms of entities, properties, interactions, inputs-outputs, and state changes over time. Mechanisms do things. They are active and so ought to be described in terms of the activities of their entities, not merely in terms of changes in their properties. ([2000], p. 5)

MDC argue that activities themselves underwrite the modal characteristics (for example, counterfactuals) of causal relations, being 'the producers of change' ([2000], p. 4), and that therefore, '[n]o philosophical work is done by positing some further thing, a law, that underwrites the productivity of activities' ([2000], p. 8).

\footnotetext{
${ }^{3}$ New Mechanists like Craver ([2007]) have sometimes adopted Woodward's ([2003]) manipulability account of causal explanation, but it is important to keep in mind that Woodward's account is intended only to be an account of 'how we think about, learn about, and reason with various causal notions and about their role in causal explanation' ([2008], p. 194), not an account of the metaphysics of causation. Additionally, Glennan has argued that the virtues of Woodward's account of the epistemology of causal reasoning '[do] not legitimate the manipulability theory as a metaphysical account of causation' ([2009], p. 318).
} 
But there is a further ontological alternative to activities that MDC must address: causal powers (also known as 'capacities' or 'dispositions'). MDC give short shrift to this alternative conception in their 2000 paper. Their remarks are confined to the following:

Substantivalists thus speak of entities with capacities (Cartwright [1989]) or dispositions to act. However, in order to identify a capacity of an entity, one must first identify the activities in which that entity engages. One does not know that aspirin has the capacity to relieve a headache unless one knows that aspirin produces headache relief. ([2000], pp. 45)

MDC therefore conclude that it is activities that are fundamental, and dispositions or capacities are ontologically secondary to them. Here, MDC have made the mistake of conflating epistemic priority with metaphysical priority. Cartwright has argued that knowledge of capacities does not reduce to knowledge of activities: 'The knowledge we have of the capacity of a feature is not knowledge of what things with that feature do but rather knowledge of the nature of the feature' ([1999], p. 78). But even if it were necessary to identify the occurrence of an activity before one could identity the capacity to engage in the activity, as MDC argue, it would not follow that the capacities are ontologically dependent on activities, and activities are therefore more fundamental.

Machamer makes a slightly different argument in a later paper:

activities are better off ontologically than some people's ontic commitments to capacities, dispositions, tendencies, propensities, powers, or endeavours. All these concepts are derivative from activities. [... T] he active exercise of a capacity has to be ontologically prior to any mysterious property called 'the ability to exercise that capacity'. ([2004], p. 30)

Instead of arguing from epistemic priority to ontic priority, Machamer is arguing from conceptual priority to ontic priority. Machamer explicitly states the underlying premise of this argument on the same page: 'being able to recognize what a capacity does when actualized or the activity that constitutes it presupposes having the concept of the activity' ([2004], p. 30). Again, there is a conflation at work: conceptual priority is not the same thing as ontological priority. But further, it's not clear that the premise itself is true. As Aristotle argued, it is only the conception of a capacity (or 'potentiality') that allows us to make sense of an entity persisting through a change in its activity (Gill [1989], pp. 185ff). Hence, it's not obvious that activities are conceptually prior to capacities.

The above arguments are not the primary reason why powers and capacities have been mostly avoided by philosophers of science. The primary reason was alluded to in the quotation from Machamer: causal powers and their ilk are often viewed by philosophers of science as something to be avoided, because they are viewed as mysterious as well as alien to science. This brings us to the next desideratum. 


\subsection{The third desideratum: Scientific validity/non-mysteriousness}

While Cartwright and Pemberton ([2013]) have argued in favour of a robust, Aristotelian account of causal powers to ground the inherent activeness of mechanisms, and others ${ }^{4}$ have understood biological causation in terms of causal powers, the New Mechanist philosophers have generally been unwilling to fully embrace an Aristotelian picture of causation that imbues the entities within mechanisms with causal powers. ${ }^{5}$ There are a couple of reasons for this. First, scientists don't tend to talk in a way that makes it obvious that they are committed to the reality of entities like powers. ${ }^{6}$ Second, it has sometimes been argued (for example, by Machamer [2004]) that causal powers are mysterious. Why believe that causal powers are more mysterious than activities (that is, the actual behaviour)? Because causal powers are dispositional. This fact, by itself, has often led philosophers to claim that causal powers are ontologically secondary to occurrent events and properties.

But what is it about dispositions that makes them mysterious? Consider what Nelson Goodman had to say on this subject:

The peculiarity of dispositional predicates is that they seem to be applied to things in virtue of possible rather than actual occurrences - and possible occurrences are for us no more admissible as unexplained elements than are occult capacities. The problem, then, is to explain how dispositional predicates can be assigned to things solely on the basis of actual occurrences and yet in due accordance with ordinary or scientific usage. ([1954], p. 42)

On Goodman's understanding, then, that which is merely dispositional cannot be actual; there is no logical space for any alternative. But Heil ([2005], [2012]) argues that this is not the only way to understand the meaning of 'dispositional'. ${ }^{7}$ When powers are conceived of as dispositions, he argues, they are conceived as something that is actual, part of the intrinsic nature of its bearers, even when not manifested. Similarly, for Harré and Madden, having a power versus not having power is not merely a difference in what objects can do, or might do, and it might not be a difference in what they will do at all. It is rather 'a difference in what they themselves now are [...] a difference in intrinsic nature' ([1975], p. 86).

Heil's way of understanding 'dispositional' opens up a way out of Machamer's mysteriousness objection. But what could it mean for something to be part of the actual, intrinsic nature of an

\footnotetext{
${ }^{4}$ For example, Gillett ([2007]), Dupré ([2007]), Deacon ([2011], pp. 364-8), Mumford and Anjum ([2011], pp. $218-$ 20), and Moreno and Mossio ([2015]).

${ }^{5}$ Glennan at times writes of capacities and powers (e.g., [2017], pp. 31-5) but they are not basic categories in his ontology and take a backseat to activities (e.g., [2017], pp. 50 and 148). This is apparently because Glennan denies that capacities are 'intrinsic features' of their bearers ([2017], p. 52). But on the other hand, and interestingly, Glennan does characterize modal 'relations of causal determination' as 'intrinsic actual-world' features ([2017], pp. 167-8).

${ }^{6}$ Cartwright has argued that a commitment to capacities or powers is 'implicit [...] in the conventional methods for causal inference' ([1989], p. 142) used by scientists, but many philosophers of science have remained unconvinced.

${ }^{7}$ See also Weissman's ([1965], pp. 84-5) criticism of Goodman's view, which anticipates Heil's argument in important respects.
} 
object, but in a non-manifested state? And can this be understood in a way that is grounded in the details of scientific practice? A positive account that answers these questions will have to wait until Section 4. I turn now to the remaining two desiderata.

\subsection{The fourth desideratum: Directionality}

Mechanistic activities are sometimes characterized as being directional. Among the New Mechanist philosophers of science, Bechtel has laid the greatest stress on the directional aspect of the activeness of mechanisms:

The term activity [...] does not readily capture the fact that in most operations there is also something acted upon. This is the reason I have preferred the term operation. Typical of the operations I have in mind are the reactions of chemistry which prototypically involve a catalyst, a reactant, a product, and often a cofactor. ([2006], p. 30; see also Bechtel [2008], p. 14)

In a similar vein, Glennan writes that 'with respect to activities that are interactions, we often distinguish between the active "doer" of the activity and the passive object of the activity' ([2017], p. 31). ${ }^{8}$ In other words, one component might play a passive role in a mechanistic operation, while another plays an active role. For example, a chaperone molecule in a cell performs the operation of folding a protein. After folding is completed, the bonding structure of the protein has changed, but the chaperone returns to its original configuration after the operation is complete. The chaperone plays an active role in the process: it changes the structure of the folding substrate without itself being substantially altered in the process (any alterations to the chaperone are readily reversed so that it can play the same role on subsequent occasions).

Several accounts of causation provide a natural interpretation for the directionality of causation. On the conserved quantity theory (Dowe [2000]), for example, one might explain directionality by reference to the fact that one component in an operation gains a quantity of energy while another loses a quantity of energy. While this might be useful for identifying the components playing an energetically active versus passive role in metabolic processes in biology (the molecule supplying the energy for a reaction might be seen as the active component), it would fail with respect to many signalling or regulatory types of processes. Any account of mechanistic causation should be able to provide a substantive story about the directionality of causation that is consistent with scientific practice.

This could potentially be another respect in which the causal powers approach has a leg up. A distinction between active and passive causal powers goes at least back to Locke, and has been

\footnotetext{
${ }^{8}$ Glennan further adds the caveat that 'this distinction is not a deep one, in the sense that all actors in an interaction produce changes in other actors, and often the active/passive distinction is a matter of degree' ([2017], p. 31). In this respect, the directionality of activities manifests one of the ways that mechanisms are perspectival, as discussed in Section 2.4.
} 
revived in the form of 'powers' versus 'liabilities' by Harré and Madden ([1975], p. 89), as well as 'backward-looking' versus 'forward-looking' powers by Shoemaker ([1998]). ${ }^{9}$

\subsection{The fifth desideratum: Perspectival nature of mechanisms}

Another one of the recurring themes in the New Mechanist literature is that mechanisms are perspectival: the boundaries and identity conditions of mechanisms are fixed, in part, by the subjective mental states (for example, interests or perspectives) of scientists. ${ }^{10}$ Specifically, what counts as a mechanism is determined not by 'what the mechanism invariably does but what we think it is supposed to do' (Craver [2013], p. 140). Craver and Bechtel write that 'there are no mechanisms simpliciter — only mechanisms for phenomena. A mechanism's phenomenon partially determines the mechanism's boundaries (i.e., what is "in" the mechanism and what is not)" ([2006], p. 469), but as Darden points out, 'the choice of phenomenon is relative to the scientist's interests' ([2008], p. 960). Craver emphasizes that 'the world does not come prechunked into mechanisms'; such chunking ineliminably will be contextually dependent on the phenomenon of interest, that is, 'some behavior that the scientist is interested, for whatever reason, in explaining' ([2013], p. 140). As a result, Craver characterizes his view as a kind of 'perspectivalism about mechanisms':

Mechanistic and functional descriptions [...] presuppose a vantage point on the causal structure of the world, a stance taken by intentional creatures when they single out certain preferred behaviors as worthy of explanation. ([2013], p. 134)

Kuhlmann and Glennan write that 'the New Mechanists agree that there is an inherent perspectivalism in the process of identifying and individuating parts' ([2014], p. 339), which in turn is key to the individuation and identity conditions of the mechanisms themselves.

This fifth desideratum, which has perhaps been most neglected in extant discussions of mechanistic causation, creates special difficulties for any attempt to provide a metaphysical account of mechanisms. Mechanistic processes are causal processes, and mechanisms are individuated relative to scientists' explanatory interests. But surely, causation itself is objective and mind-independent (otherwise, an enormous amount of ink has been spilled on the mind-body problem and the causal exclusion problem for nothing!). Further: above, I said that I would take for granted the New Mechanist view that 'mechanisms are real systems in nature'. How do we square this with the 'inherent perspectivalism' of the individuation and identity conditions of mechanisms?

\footnotetext{
${ }^{9}$ It should be noted that a distinct notion of 'directionality' or 'directedness' pertaining to dispositions was discussed by Martin and Pfeifer ([1986]) and Molnar ([2003]). 'Directionality' in their sense merely refers to the relation between a disposition and its manifestations.

${ }^{10}$ This point was made earlier by Polányi ([1958], p. 357), Kauffman ([1971], pp. 259-60), and Glennan ([1996], p. $52)$.
} 
In the discussion leading up to Section 2.4, I have been drumming up the merits of causal powers as an approach to understanding the metaphysical underpinnings of mechanisms. But the causal powers approach does not offer much help once we consider the perspectival nature of mechanisms, and if anything, the causal powers approach only compounds the difficulties. MDC characterize causal powers approaches as fundamentally substantivalist; they are correct in the sense that an attribution of causal powers typically presupposes some scheme of individuation. On the usual picture of causal powers, they are instantiated by individuals. To the extent that the individuation of mechanistic parts is dependent on the perspectives taken by scientists, then, the individuation of causal powers will be as well. In other words, powers are relative to a stance that one takes about what counts as an individual and what does not. ${ }^{11}$

Among the traditional options, causal powers are the best way to conceptualize mechanistic causation, but they cannot metaphysically be the end of the story. Instead, a new approach is needed that provides the necessary metaphysical foundation for understanding both causal powers and mechanistic causation and also satisfies the five desiderata. It is to this new approach that I now turn.

\section{Constraints and Causation}

\subsection{Multi-Perspectival realism and causal structure}

A new type of 'multi-perspectival realism' (to use Wimsatt's [2007] terminology) has been emerging that can offer us guidance to finding the right metaphysical account of mechanistic causation. Sandra Mitchell, for example, writes:

I will argue for a pluralist-realist approach to ontology, which suggests not that there are multiple worlds, but that there are multiple correct ways to parse our world, individuating a variety of objects and processes that reflect both causal structures and our interests. ([2009], p. 13; see also Glennan [2017], p. 93)

Note that Mitchell takes the value of the approach to lie in the fact that it reflects our interests on the one hand, and causal structures on the other. On her view, the causal structures themselves exist out in the world, independently of human interests and perspectives, but we may adopt more than one perspective or 'ways of parsing' to talk about them. In the words of Gordon Globus, 'there is a "reality" independent of perspective, and that "reality" is structure' ([1976], p. 282). So there are really two levels of realism here: a perspectival realism about objects and processes, and a non-perspectival realism about causal structures themselves. But the success of this approach

\footnotetext{
${ }^{11}$ Additionally, Heil ([2012], pp. 118-9) argues that distinctions that are made between active and passive roles for causal powers in causation are ineliminably perspectival even if powers themselves are not.
} 
hinges on the questions: what are 'causal structures'? In what sense are they 'real'? What is their metaphysical nature? Can they really do the work Mitchell needs them to do?

Wimsatt seems to make a similar kind of move, arguing that while scientists take multiple perspectives on how the world is carved up,

this multiple rootedness need not lead to 'anything goes' perspectival relativism, or an antinaturalist worship of common sense, experience, or language. It yields a kind of multiperspectival realism anchored in the heterogeneity of 'piecewise' complementary approaches common in biology and the study of complex systems. ([2007], p. 12)

Like Mitchell, Wimsatt appeals a notion of causal structure that underwrites such perspectives:

Ontologically, one could take the primary working matter of the world to be causal relationships, which are connected to one another in a variety of ways - and together make up patterns of causal networks. [...] These networks should be viewed as a sort of bulk causal matter - an undifferentiated tissue of causal structures [...] Under some conditions, they are so richly connected that neither perspectives nor levels seem to capture their organization, and for this condition, I have coined the term 'causal thickets'. ([1994], p. 220)

The question, again, is: How are we to characterize this 'bulk causal matter' or causal-structural 'tissue'? 'Thicket'... of what?

\subsection{Causal structure as laws}

The traditional way that philosophers have metaphysically characterized causal structures is by positing laws as something ontologically free-standing. ${ }^{12}$ Historians such as John Henry have traced this tradition back to Descartes. According to Henry ([2004]), it was Descartes who was primarily responsible for effecting a shift from the conception of causality as resulting from the intrinsic nature of things, as on the Aristotelian view, to a conception of causality as resulting from laws that are external to physical objects. Henry argues that before Descartes, the notion of a 'natural law' was primarily only invoked to refer to regularity in nature; such usages of 'law' were only descriptive and not explanatory. However, 'laws' in themselves became central to explanation for Descartes because he considered causal efficacy itself to be located within laws, rather than merely described by them.

Funkenstein ([1986]) argues that Descartes rejected the idea of physical objects having causal efficacy as part of their intrinsic nature because this was incompatible with his epistemology. Specifically, Descartes's 'skeptical analysis of sense perceptions' led to the result that

\footnotetext{
12 Salmon, who played an important role in the development of the New Mechanist philosophy, did not see causal structures as identical with laws, but instead as 'governed' by them ([1984], p. 132).
} 
'matter' (the object of sense perception) is first and foremost extension, for extension is the only determination of matter perceived 'clearly and distinctly'. Mathematical relations (and geometry, for Descartes, is throughout quantifiable) constitute all that is known and all that can be known about matter. (Funkenstein [1986], p. 184)

As a result, matter for Descartes was causally inert in itself. Henry argues that for Descartes, the idea of laws themselves being explanatory, which was novel at the time, was likely inspired by his background in mathematics. But in order to explain physical events, they also had to be causal. At the time of Descartes, the only intuitively plausible alternative to physical matter having intrinsic causal powers was to conceive of things as instead being caused by God. Henry argues that the idea of inanimate bodies being independently capable of 'obeying' laws of nature would have been seen as an 'awkward inherent implication' of Descartes's position, had he not attributed the role of executing such laws to God.

Eventually, however, Henry's argument continues, people's intuitions shifted so that the idea of inert matter operating according to laws became the conventional and default way of looking at physics. Boyle and Newton still conceived of natural laws as ultimately dependent on God for their execution, but by the nineteenth century, the idea of laws as being ontologically fundamental and free-standing, and as being the ultimate source of causal efficacy (or 'self-executing', as it were), became commonplace. This was reinforced, of course, by the success of Newtonian mechanics, in which laws were taken to play a central explanatory role. Newton, who shared Descartes's goal of creating a mathematical system of mechanics, followed Descartes in rejecting the idea of causal powers that inhered within physical objects, and adopted a view of matter as causally inert and governed by laws. The Cartesian conception of a universe of physical objects causally directed by laws that were extrinsic to those objects continued as the dominant metaphysical picture for philosophers well into the twentieth century. On this picture, matter has no intrinsic causal structure of its own; causal explanations must therefore refer to the laws.

It is important to note at this point that although Newtonian mechanics speaks of 'laws', it is not committed to any particular metaphysical picture. From here on, I will use 'Cartesian laws' to refer to the metaphysical conception of laws as universal and extrinsic to matter, and 'Newtonian laws' to refer merely to equations of motion as formulated by Newtonian mechanics (abstracted from any given metaphysical interpretation).

\subsection{Causal structures in analytical mechanics: Constraints}

The Newtonian formulation of mechanics is the one that philosophers generally associate with 'classical mechanics'. But later formulations, now referred to as analytical mechanics - such as that of Joseph-Louis Lagrange, introduced in the eighteenth century, and that of William Rowan Hamilton, introduced in the nineteenth - are different from Newtonian mechanics in two ways that I wish to highlight: 
- Whereas the Newtonian formulation relies only on motion equations, analytical mechanics introduces constraint equations.

- Whereas the Newtonian formulation always expresses motion using Cartesian coordinates, analytical mechanical methods often involve switching to a new coordinate system (referred to as generalized coordinates) that is tailored to the problem at hand.

Though it remains possible (in principle) to describe any classical system using the Newtonian formulation, the innovations of analytical mechanics allow many types of problems to be expressed in a far more economical and practical manner. This is because there are many types of patterns and structure that can be represented and exploited by analytical mechanics that cannot be represented and exploited by Newtonian mechanics. Take for example a rigid object composed of many particles. In Newtonian mechanics, the system will require six variables for each particle (location and velocity in three dimensions), and a separate equation for each particle. This becomes quite unwieldy for systems with a large number of particles. Instead, analytical methods allow reduction of the entire system to a single equation by adopting a 'generalized' coordinate system that might consist of only eight variables, representing degrees of freedom (three each for location of the centre of mass and velocity, and two for angles of rotation about the centre of mass) for the rigid object as a whole. ${ }^{13}$

The transformation from Cartesian coordinates to generalized coordinates begins with the addition of constraint equations. Whereas the motion equations describe how the coordinate variables will change over time, constraint equations describe limitations on how they can change. In cases where the constraint equations are not too complex (for example, when they do not have to be expressed using differential equations, in which cases the constraints are referred to as holonomic), analytical methods may be applied to the motion and constraint equations to derive a new description of the system in terms of motion equations in a generalized coordinate system. It is important to realize, however, that in such cases, the constraints have not ceased to exist; they are merely implicit and are now incorporated into the new 'laws of motion' of the system. The new 'laws of motion', that is, the equations that describe the system, are not laws in Descartes's sense; they are equations that only apply locally to the system that has been so redescribed. In many other cases, however, constraint equations cannot be eliminated by analytical means. I will refer to the former cases as 'holonomic systems', and the latter as 'non-holonomic systems' ${ }^{14}$ Holonomic systems will include cases like rigid objects; non-holonomic cases will include systems with complex, machinelike dynamics, notably including protein molecules, which make up the building blocks and machinery of all biological systems (Pattee [1973]).

\footnotetext{
${ }^{13}$ For recent textbooks that deal with these topics, see Goldstein, Poole, and Safko ([2002]) and Taylor ([2005]).

${ }^{14}$ Technically this is not quite accurate because analytical methods do exist for producing constraint-free formulations of some relatively simple non-holonomic systems (specifically, those that fall under the scope of D'Alembert's principle), but this technicality will be of no consequence in what follows, since biological systems are of much greater dynamical complexity (Pattee [1973]).
} 
The need for formulations other than that of Newton arises because there is a great deal of causal structure that Newtonian equations do not describe; not all structure is microstructure (Mitchell [2012]). ${ }^{15}$ Much of this causal structure is confined locally; this is why it is often useful to adopt problem-specific constraint equations or coordinate systems. The Newtonian formulation only exploits facts about causal structure that hold true in all parts of space and time, for all kinds of (classical) dynamical systems. This is why it expresses all problems in the same, Cartesian, coordinate system. Dynamical systems include a great deal of structure that is not described by Newtonian mechanics, and non-holonomic systems have dynamics that cannot be described without reference to constraints. What are the metaphysical implications?

\subsection{A metaphysics inspired by analytical mechanics: Constraints as ontologically primitive modal structures}

In order to account metaphysically for the fact that Newtonian motion equations capture causal structure on the particle level, and generalized motion equations and constraint equations capture larger and higher-order causal patterns, there are three options:

1. Treat both motion equations and constraint equations as true in virtue of Cartesian laws, placing causal efficacy within ontologically robust, standalone entities that are extrinsic to all objects and dynamical systems.

2. Treat motion equations as true in virtue of ontologically robust, extrinsic entities (Cartesian laws), and constraint equations as true in virtue of the intrinsic causal structure of constrained systems (so that causal efficacy is partly extrinsic to objects in the world and partly intrinsic).

3. Treat both motion equations and constraint equations as true in virtue of causal structure that is intrinsic to the particles, objects, and dynamical systems themselves.

In my view, Occam's razor and other considerations clearly favour the third option. The first option would require non-universal extrinsic principles of motion that undergo continual change (as local constraints continually change, and dynamical systems become describable in terms of different kinds of constraint equations). Most of the appeal of regarding principles of motion as extrinsic to objects is supposed to derive from their being the universal and unchanging anchors of physical explanation. Option one would defeat this basic appeal. Option one also leaves the dynamics of non-holonomic systems unaccounted for. Option two locates causal efficacy partly within extrinsic laws and partly within intrinsic natures. Some advocates of 'strong emergence' have proposed such a metaphysics. ${ }^{16}$ But given that some systems (for example, holonomic systems) could equally be described either in terms of motion equations alone or in terms of a combination of motion and constraint equations, it does not make sense to argue that there is a single, objective partitioning in nature between extrinsic and intrinsic causal principles of motion.

\footnotetext{
${ }^{15}$ Further, not all causal structure is reducible to microstructure (Wimsatt [1994]; Mitchell [2012]).

${ }^{16}$ For critical discussion of such views, see Klee ([1984]).
} 
The preferable option is the third, that is, the metaphysical idea that causal structure in general is something local to and inherent within mechanical systems, waiting to be discovered and exploited by means of various choices of motion equations, constraint equations, and coordinate transformations. Systems can be described by these means because they intrinsically possess systematic limitations on how they can change. On option 3, causal structure refers precisely to such intrinsic systematic limitations and is ontologically primitive (that is, it is not grounded in an extrinsic principle of change like Cartesian laws). Like Ross, Ladyman, and Spurrett ([2007]), and in order to mark the departure from the Cartesian metaphysics of laws, I will refer to such ontologically primitive, intrinsic limitations as 'constraints'. On this view, constraints are more than mere regularities; in the words of Mumford ([2004]), constraints are 'modally loaded'. They may be thought of as modal patterns. Often, patterns are conceived in philosophy as nothing more than non-modal regularities. But constraints are more than just occurrent regularities; constraints in a dynamical system pertain to what might happen. They are the modal facts about a dynamical system, the truthmakers for dynamical equations and modal causal claims.

This conception of causal structure is cognate with French's 'modal structuralism' which 'takes the structure to be "inherently" modal' ([2014], p. 263) and Esfeld's ([2009]) conception of 'causal structures'. French ([2006], p. 183) argues that there is nothing inherent to the concept of a structure that makes it any less causal than other ontological categories like properties. French also draws inspiration from Maudlin ([2007]) to make a positive argument for his modal structuralism. Maudlin argues that

nothing in scientific practice suggests that one ought to try to reduce fundamental laws to anything else. [...] The practice of science, I suggest, takes fundamental laws of nature as further unanalyzable primitives. As philosophers, I think we can do no better than to follow this lead. ([2007], p. 105)

French carries this reasoning further, arguing that the practice of physics shows that physicists treat laws as structures that are causal, unanalysable, and primitively modal ([2014], p. 298). As I have argued, however, looking at scientific practice leads us not to the Cartesian conception of causal structure as extrinsic laws, but instead to a conception of causal structure as intrinsic constraint. This argument is only strengthened when we realize that quantum mechanics is itself an offshoot of analytical mechanics, not Newtonian mechanics (Dirac [1958], p. 114).

The present view is a rejection of the Cartesian metaphysical account of laws. But it is not necessarily a rejection of the idea of a 'law' tout court. Ashby ([1956], p. 130) characterized laws as merely a special case of physical constraints that apply universally. Similarly, Glennan ([2017], pp. 3 and 44-6) characterizes laws as generalizations about local, intrinsic causal structures. But these need not be universal. Cartwright ([1999]), for example, argues that empirical evidence does not support universal generalizations, and that what are called 'laws' are generally only true within the scope of local 'nomological machines'. 
These considerations support the view that mechanical systems inherently contain a 'thicket' of constraints. It is our choice how to represent these constraints, that is, how to 'parse our world' (to use Mitchell's phrase) and individuate individuals and processes - the task accomplished in analytical mechanics by choosing which coordinate system and/or constraint equations to adopt. A constraints-based metaphysics provides a more comprehensive way to understand causal structure that is rooted in scientific practice.

\section{Constraints and Mechanistic Causal Powers}

I now return to two questions raised but not yet answered from Section 2: What could it mean for something to be part of the actual, intrinsic nature of an object, but in a non-manifested state? And can this be understood in a way that is grounded in the details of scientific practice?

\subsection{Inter- versus intra-perspectival categories}

As physicist and theoretical biologist Howard Pattee explained, constraint is really an interperspective concept, rather than an intra-perspective one. This is because the concept of a constraint is really the concept of a set of possibilities that is reduced to a smaller number of possibilities. Describing something as a constraint implies at least two ways of carving the world. This can be seen in the example of the rigid object composed by particles, which might allow a change in coordinate systems. By referring to the rigid object as constrained, one makes implicit reference to the fact that without the constraint, the system would consist of particles with many more degrees of freedom:

constraints must be defined by different descriptive levels. [...] Why are these necessarily two-level processes? Why are two distinct descriptions necessary? Because we cannot speak of an event as being both possible and impossible using the same level of description. On the lower, unconstrained level the alternatives must be possible; for if they were impossible then deciding for or against them would be a vacuous process. But on the upper, constrained or controlled level, $[\ldots]$ some of these alternatives are actually selected, or more precisely, made more probable [...] (Pattee [1972], p. 84)

For this reason, writes Pattee, 'whenever a physicist adds an equation of constraint to the equations of motion, he is really writing in two languages at the same time' ([1973], p. 98). Constraints require some kind of stuff in order to be instantiated, but their instantiation does not depend on how the underlying stuff is ontologically 'carved' into objects, or what Lloyd Morgan called the 'substantial gotogetherness' ([1927], p. 193) of the stuff. This is a key difference between constraints and powers. Powers emerge once one adopts a world-carving perspective; constraints are the preconditions in the world that underwrite the adoption of such perspectives.

Return to the example of the chaperone and substrate molecules. From one perspective, each is a collection of atoms held together in a certain way by bonds. From another perspective, each is an 
object constrained to possess a certain shape. Neither of these perspectives is the 'right' one; they merely represent distinct 'ways of parsing' the world. However, in each case the same underlying, invariant causal structures (whether we conceptualize them as configurations of bonds between atoms or as shapes of objects) — constraints—are determining how the system will behave.

It might be argued that when we abstract away from object-oriented ways of carving up the world, and merely refer to the universe as consisting of an uncarved expanse of 'stuff' that is constrained in various ways in various locations, we are still adopting a 'perspective'. Yes, but this will by definition not be a world-carving perspective. When I say that constraint is an inter-perspectival ontological category, I mean that it is an ontological category that is independent of any perspective on where the boundaries between objects (events, processes, and so on) are. It is an ontological category that picks out the full range of real causal patterns in the world which are the candidates for populating such world-carving schemes; any world-carving perspective will selectively isolate a subset of such causal patterns to form the basis of its parcellation into objects, events, processes, and so on.

The key difference between powers and constraints, namely that powers are applicable to objectoriented ways of carving up the world, whereas constraints are inter-perspectival, demonstrates why it is necessary to have both categories. Here it is helpful to recall MDC's claim that causal powers are 'substantivalist'. In the framework of mechanistic explanation, any power instance is the power of some object (that is, of a mechanism or part of a mechanism); if the object goes out of existence (that is, its identity conditions no longer obtain), its powers do as well. Unlike causal powers, constraints don't go away when you change ontological perspectives. ${ }^{17}$

\subsection{Mechanistic causal powers are grounded by constraints}

My main suggestion in this paper is that we adopt a multi-perspectival realist approach to understanding mechanistic causation. Again, multi-perspectivalism involves two levels of realism: a perspectival realism about objects and processes, and a non-perspectival realism about causal structures themselves. ${ }^{18}$ Correspondingly, a metaphysical account of mechanistic causation must involve perspectival realism about causal powers, and non-perspectival realism about constraints. Mechanisms, being physical systems, are constituted by physical stuff; as such, constitution is a relation that can transcend world-carving perspectives. Then what is the relation between constraints and causal powers? The relation cannot be identity, since something that is real relative

\footnotetext{
${ }^{17}$ It should be noted that while most ways of conceiving causal powers tie them to objects or processes, this is not true of all ways of conceiving causal powers. For example, Marmodoro ([2017]) makes a distinction between structural powers and substantial powers; her 'substantial power' corresponds to my use of 'power', and her 'structural power' is closer to what I am calling 'constraint'.

${ }^{18}$ Ross, Ladyman, and Collier provide reasons why 'our local actual (physical) circumstances [might] be such that constructing individuals is necessary for tracking some extra-representational real patterns' ([2007], p. 245). What they refer to as 'locally dynamic real patterns' (e.g., [2007], p. 252) seems to be the same as what I am calling 'constraints'. Later in the same book, Ross, Ladyman, and Spurrett ([2007], p. 288) use the word 'constraint'.
} 
to a perspective will not have the same identity conditions as something that is real independently of perspective. Instead, the relation is a certain kind of ontological dependence: the constraints, that is, the perspective-independent causal structures, are what make it possible to usefully adopt a causal powers perspective. When we adopt an object-oriented perspective, the way that the stuff constituting an object is dynamically constrained allows us to talk instead of powers that the object has. ${ }^{19}$ Constraints are the truthmakers for modal facts about the dynamics of a system; when looked at from a perspective that parcels the system into objects and properties, these modal facts map onto dispositional facts about such objects and properties. In other words, they serve as the intrinsic and actual grounding of perspectival facts about what kinds of behaviours will manifest under certain conditions.

The causal powers approach seemed like a promising way to account for mechanistic causation until we saw that it could not meet two of the desiderata in a way that practice-oriented philosophers of science would consider fully satisfactory: scientific validity/non-mysteriousness, and the perspectival nature of mechanisms. However, if we can account for causal powers ontologically in terms of constraints, we will have an account of causal powers that is wellgrounded in the details of scientific practice; Paul Davies writes that 'in almost every branch of physics, with the possible exception of elementary particle physics, constraints play a crucial role', ([1989], p. 104). Further, whereas resorting to causal powers alone does not provide a nonperspectival grounding of mechanistic causation, constraints offer a way to account for the underlying causal structure that underwrites causal powers perspectives.

The present account of mechanistic causation will not be complete, however, until it is explained how constraints can ground the other aspects of causal powers that allow them to satisfy the remaining three desiderata: intrinsicness, productivity, and directionality.

\subsection{Intrinsicness and constraints}

Unlike laws, constraints are local to the system that possesses them. The local, intrinsic aspect of constraints has been emphasized by a number of authors who have applied the concept of a physical constraint to a wide range of contexts. ${ }^{20}$ It is important to note here that sometimes authors have distinguished between 'intrinsic' and 'extrinsic' constraints, or 'internal' and 'external' constraints. For example, 'constraints may be external owing to the environment interacting with the system. Or such constraints may arise internally within the system owing to the collective effects of its constituents or the evolving dynamics' (Bishop [2012], p. 5). Deacon uses the words 'intrinsic' and 'extrinsic': 'constraints can originate intrinsic or extrinsic to the system that is

\footnotetext{
${ }^{19}$ Juarrero ([1999], pp. 131-2) and Moreno and Mossio ([2015], p. 51) have also proposed that constraints can ground causal powers. Cartwright and Pemberton ([2013], p. 96) reverse the order of priority and hold that 'constrainings' result from causal powers.

${ }^{20}$ For example, situation theory (Barwise and Perry [1983], p. 98), theoretical biology (Pattee [1982], p. 176), cybernetics (Ashby [1956], p. 131), information theory (Deacon [2007], pp. 127ff.), behavioural science (Kelso [1995]), ecological psychology (Greeno [1994]), and Gestalt theory (Köhler [1922/1967], pp. 61-2 and 68-9).
} 
thereby constrained' ([2011], p. 549). The distinction between intrinsic and extrinsic constraints is important in thermodynamics, for example (Nicolis and Prigogine [1977]).

However, these are just different ways of talking about metaphysically intrinsic constraints. Hooker ([2013], p. 760) argues that any system that is described in terms of external constraints between subsystems can be re-described in terms of the internal constraints of the larger containing system. But he argues that this does not in any way diminish the reality of the constraints themselves; it is only the characterization of them as internal versus external that is perspectival. For example, in the case of Rayleigh-Bénard convection, the Bénard cells that form are themselves internal constraints of the boiling water that result from the external constraints of the water's metal container and the heat source. Nothing stops us from describing it as a single system that contains the heat source, metal container, and the Bénard cells themselves as internal constraints. But this does not show that constraints are not local or intrinsic to dynamical systems. It shows, instead, that constraints remain regardless of the perspective we take on the portion of physical stuff that is constrained. We can talk about that stuff as being a single object, or a set of objects, or a portion of a larger object; in all of these cases, we are talking about the same locally constrained stuff in different ways. One is not more fundamental than the other.

\subsection{Constraints and productiveness}

In Section 3.4, I defined constraints as ontologically primitive intrinsic limitations on how dynamical systems can change. But how is the idea of something limiting the possibilities for change of a system compatible with its producing the resulting changes? In one sense, of course, constraints are limiting, and reduce the degrees of freedom of a system. But in another sense, constraints are enabling, and they shape and define the types of behaviours a system will have, as Cliff Hooker explains:

$[\ldots]$ constraints can at the same time also be enabling, they can provide access to new states unavailable to the unconstrained system: equivalently, by coordinatedly decreasing degrees of freedom they provide access to dynamical trajectories inaccessible to the unconstrained system. [...] a skeleton is a disabling constraint, for example limiting the movements of limbs (cf. an octopus), but by providing a jointed frame of rigid components for muscular attachments it also acts to enable a huge range of articulated motions and leverages ([2013], p. 761; see also Pattee [1973])

To see how productivity results from constraint, consider what a dynamical system would be like if it were absolutely unconstrained. From one moment to the next, all configurations or statetransitions would be equally probable. It would not be possible to make any kind of predictions about the system (or, for that matter, to take an object-oriented perspective on events going on in the system). All predictability requires redundancy, which is nothing more or less than a way that a system is constrained. Whenever we can isolate systematic or predictable behaviours or forces within a system, that reflects a way in which the system is organized. Therefore, writes Ashby, 'the presence of "organization" between variables is equivalent to the existence of a constraint in 
the product-space of the possibilities' ([1962], p. 257). When we put this fact together with the recognition that productive relations within mechanisms exist in virtue of the causal organization that mechanisms possess (Glennan [2017], p. 23) —causal organization which underwrites and makes possible the taking of any mechanistic perspective - the sense in which productive relations within biological systems derive from how such systems are constrained becomes clear.

\subsection{Constraints and directionality}

Recall Bechtel's and Glennan's point above that in most mechanistic operations, there is both something that acts and something that is acted upon. A mechanistic perspective will therefore usually be one that posits directional causal powers: the operation will involve an active component and a passive component, and the effects will be explained in terms of active powers of the active component and passive powers of the passive component. An account of how constraints ground causal powers should provide a story about how directional powers are grounded.

In Section 4.3, I considered the fact that a dynamical system may contain subsystems, and that we can then distinguish between the subsystem's internal and external constraints. Its internal constraints are instantiated by the stuff that constitutes the subsystem; the external constraints are instantiated by stuff that is external to it. Since a passive power is the ability of something to be causally affected in a certain way by something external to it, a passive power can only be instantiated by an object constituted by stuff that is both internally and externally constrained in certain ways. Specifically, I consider passive powers to emerge from a kind of second-order constraint:

A passive causal power exists when a system within a larger system is internally constrained in such a way as to be externally constrained under certain conditions.

Similarly, active causal powers (of the kind that result in causal effects within external objects) also emerge from a kind of second-order constraint:

An active causal power exists when a system within a larger system is internally constrained in such a way as to externally constrain under certain conditions.

We can now revisit the example of the chaperone molecule performing the operation of folding a substrate protein. The chaperone plays an active role in the process, since it changes the structure of the folding substrate without itself being changed in the relevant way by that process. The chaperone has the active causal power to fold the substrate: it has an internal bond structure that will allow it to externally constrain the structure of the substrate after the substrate bonds to the chaperone. After folding is completed, the bonding structure of the substrate has changed, but the chaperone returns to its original configuration. The substrate had the passive causal power to be folded: it had an internal bond structure that would allow it to be recognized by the chaperone and to be folded by it. 
Keep in mind that there is nothing ontologically profligate about countenancing second-order constraints; constraints are merely a type of structure, and any account of structure will include higher-order structures. There are of course many orders of structure within biological systems, and this is key to Wimsatt's notion of 'causal thickets'. Because these higher orders of structure are indispensable to biological explanation, as well as to the other 'sciences of complexity' (Stein [1989]), we should acknowledge that primitive modality may also accompany these higher orders.

\section{Conclusion}

In this paper, I have argued that extant accounts of the metaphysics of mechanistic causation do not succeed because they fail to satisfy five key desiderata that have emerged in recent New Mechanist literature. I offered a novel multi-perspectivalist approach to understanding mechanistic causation which incorporates two levels of realism: a perspectival realism about objects (mechanisms and their parts) and their causal powers, and a non-perspectival realism about the causal structures that underwrite these perspectives. I further showed how the conception of nonperspectivally real causal structures can be cashed out in terms of a concept that has long been familiar to science but that has been mostly neglected by philosophers: constraints. Finally, I demonstrated how a constraints-based account has the resources to satisfy the five desiderata, and to provide a non-perspectival grounding for mechanistic causation.

\section{Acknowledgements}

Thanks to Maria Şerban, Sara Green, Kerry McKenzie, William Bechtel, Nancy Cartwright, Anna Marmodoro, John Heil, John Pemberton, two anonymous reviewers for this journal, and audiences at the University of Durham and Oxford University for invaluable comments on earlier drafts.

Department of Philosophy and Cognitive Science Interdisciplinary Program University of California, San Diego La Jolla, CA, USA

jason.winning@gmail.com

\section{References}

Ashby, W. R. [1956]: An Introduction to Cybernetics, London: Chapman and Hall. Ashby, W. R. [1962]: 'Principles of the Self-Organizing System', in H. von Foerster and G. W. Zopf (eds), Principles of Self-Organization, New York: Pergamon, pp. 255-78. Barwise, J. and Perry, J. [1983]: Situations and Attitudes, Cambridge, MA: Bradford. 
Bechtel, W. [2006]: Discovering Cell Mechanisms: The Creation of Modern Cell Biology, Cambridge: Cambridge University Press.

Bechtel, W. [2008]: Mental Mechanisms: Philosophical Perspectives on Cognitive Neuroscience, New York: Routledge.

Bechtel, W. and Abrahamsen, A. [2005]: 'Explanation: A Mechanist Alternative', Studies in History and Philosophy of Biological and Biomedical Sciences, 36, pp. 421-41.

Bishop, R. C. [2012]: 'Fluid Convection, Constraint and Causation', Interface Focus, 2, pp. 412.

Cartwright, N. [1989]: Nature's Capacities and Their Measurement, Oxford: Clarendon.

Cartwright, N. [1999]: The Dappled World: A Study of the Boundaries of Science, Cambridge: Cambridge University Press.

Cartwright, N. and Pemberton, J. [2013]: 'Aristotelian Powers: Without Them, What Would Modern Science Do?' in R. Groff and J. Greco (eds), Powers and Capacities in Philosophy: The New Aristotelianism, New York: Routledge, pp. 93-112.

Craver, C. F. [2007]: Explaining the Brain: Mechanisms and the Mosaic Unity of Neuroscience, Oxford: Clarendon.

Craver, C. F. [2013]: 'Functions and Mechanisms: A Perspectivalist View', in P. Huneman (ed.), Functions: Selection and Mechanisms, Dordrecht: Springer, pp. 133-58.

Craver, C. F. and Bechtel, W. [2006]: 'Mechanism', in S. Sarkar and J. Pfeifer (eds), The Philosophy of Science: An Encyclopedia, New York: Routledge, pp. 469-78.

Darden, L. [2008]: 'Thinking Again about Biological Mechanisms', Philosophy of Science, 75, pp. 958-69.

Davies, P. C. W. [1989]: 'The Physics of Complex Organisation', in B. Goodwin and P. Saunders (eds), Theoretical Biology: Epigenetic and Evolutionary Order for Complex Systems, Edinburgh: Edinburgh University Press, pp. 101-11.

Deacon, T. W. [2007]: 'Shannon-Boltzmann-Darwin: Redefining Information (Part 1)', Cognitive Semiotics, 1(Fall 2007), pp. 123-48.

Deacon, T. W. [2011]: Incomplete Nature: How Mind Emerged from Matter, New York: W. W. Norton.

Dirac, P. A. M. [1958]: The Principles of Quantum Mechanics (4th ed.), Oxford: Clarendon.

Dowe, P. [2000]: Physical Causation. Cambridge: Cambridge University Press.

Dupré, J. [2007]: The Constituents of Life, Amsterdam: Van Gorcum, reprinted in J. Dupré, Processes of Life: Essays in the Philosophy of Biology, Oxford: Oxford University Press, [2012].

Esfeld, M. [2009]: 'The Modal Nature of Structures in Ontic Structural Realism', International Studies in the Philosophy of Science, 23(2), pp. 179-94.

French, S. [2006]: 'Structure as a Weapon of the Realist', Proceedings of the Aristotelian Society, 106, pp. 167-85.

French, S. [2014]: The Structure of the World: Metaphysics and Representation, Oxford: Oxford University Press.

Funkenstein, A. [1986]: Theology and the Scientific Imagination: From the Middle Ages to the Seventeenth Century, Princeton, NJ: Princeton University Press.

Gill, M. L. [1989]: Aristotle on Substance: The Paradox of Unity, Princeton, NJ: Princeton University Press.

Gillett, C. [2007]: 'Understanding the New Reductionism: The Metaphysics of Science and Compositional Reduction', Journal of Philosophy, 104(4), pp. 193-216. 
Glennan, S. [1996]: 'Mechanisms and the Nature of Causation', Erkenntnis, 44(1), pp. 49-71.

Glennan, S. [2009]: 'Mechanisms', in H. Beebee, C. Hitchcock, and P. Menzies (eds), The Oxford Handbook of Causation, Oxford: Oxford University Press, pp. 315-25.

Glennan, S. [2017]: The New Mechanical Philosophy, Oxford: Oxford University Press.

Globus, G. G. [1976]: 'Mind, Structure, and Contradiction', in G. G. Globus, G. Maxwell, and I. Savodnik (eds), Consciousness and the Brain: A Scientific and Philosophical Inquiry, New York: Plenum, pp. 271-93.

Goldstein, H., Poole, C. and Safko, J. [2002]: Classical Mechanics (3rd ed.), San Francisco: Addison Wesley.

Goodman, N. [1954]: Fact, Fiction, and Forecast, Cambridge, MA: Harvard University Press.

Greeno, J. G. [1994]: 'Gibson's Affordances', Psychological Review, 101(2), pp. 336-42.

Harré, H. R. and Madden, E. H. [1975]: Causal Powers: A Theory of Natural Necessity, Oxford: Basil Blackwell.

Heil, J. [2005]: 'Dispositions', Synthese, 144, pp. 343-56.

Heil, J. [2012]: The Universe as We Find It, Oxford: Clarendon.

Henry, J. [2004]: 'Metaphysics and the Origins of Modern Science: Descartes and the Importance of Laws of Nature', Early Science and Medicine, 9(2), pp. 73-114.

Hooker, C. A. [2013]: 'On the Import of Constraints in Complex Dynamical Systems', Foundations of Science, 18(4), pp. 757-80.

Juarrero, A. [1999]: Dynamics in Action: Intentional Behavior as a Complex System, Cambridge, MA: MIT Press.

Kauffman, S. A. [1971]: 'Articulation of Parts Explanation in Biology and the Rational Search for Them', in R. C. Buck \& R. S. Cohen (eds), PSA 1970, Dordrecht: D. Reidel, pp. $257-$ 72.

Kelso, J. A. S. [1995]: Dynamic Patterns: The Self-Organization of Brain and Behavior, Cambridge, MA: Bradford.

Klee, R. L. [1984]: 'Micro-Determinism and Concepts of Emergence', Philosophy of Science, 51(1), pp. 44-63.

Köhler, W. [1967]: 'Some Gestalt Problems', in W. D. Ellis (ed., trans.), A Source Book of Gestalt Psychology, New York: Humanities, pp. 55-70. (Original work published [1922])

Kuhlmann, M. and Glennan, S. [2014]: 'On the Relation Between Quantum Mechanical and Neo-Mechanistic Ontologies and Explanatory Strategies', European Journal for Philosophy of Science, 4(2), pp. 337-59.

Machamer, P. [2004]: 'Activities and Causation: The Metaphysics and Epistemology of Mechanisms', International Studies in the Philosophy of Science, 18(1), pp. 27-39.

Machamer, P., Darden, L. and Craver, C. F. [2000]: 'Thinking about Mechanisms', Philosophy of Science, 67(1), pp. 1-25.

Marmodoro, A. [2017]: 'Power Mereology: Structural versus Substantial Powers', in M. Paolini Paoletti and F. Orilia (eds), Philosophical and Scientific Perspectives on Downward Causation, New York: Routledge, pp. 110-27.

Martin, C. B. and Pfeifer, K. [1986]: 'Intentionality and the Non-Psychological', Philosophy and Phenomenological Research, 46(4), pp. 531-54.

Maudlin, T. [2007]: The Metaphysics Within Physics, Oxford: Oxford University Press.

Mitchell, S. [2009]: Unsimple Truths: Science, Complexity and Policy, Chicago: University of Chicago Press. 
Mitchell, S. [2012]: 'Emergence: Logical, Functional, and Dynamical', Synthese, 185, pp. 17186.

Molnar, G. [2003]: Powers: A Study in Metaphysics, Oxford: Oxford University Press.

Moreno, A. and Mossio, M. [2015]: Biological Autonomy: A Philosophical and Theoretical Enquiry, Dordrecht: Springer.

Morgan, C. L. [1927]: Emergent Evolution (2nd ed.), London: Williams and Norgate.

Mumford, S. [2004]: Laws in Nature, London: Routledge.

Mumford, S. and Anjum, R. L. [2011]: Getting Causes from Powers, Oxford: Oxford University Press.

Nicolis, G. and Prigogine, I. R. [1977]: Self-Organization in Nonequilibrium Systems: From Dissipative Structures to Order Through Fluctuations, New York: Wiley.

Pattee, H. H. [1972]: 'Laws and Constraints, Symbols and Languages' reprinted in H. H. Pattee and J. Rączaszek-Leonardi (eds), Laws, Language and Life, Dordrecht: Springer, pp. 819, [2012].

Pattee, H. H. [1973]: 'The Physical Basis and Origin of Hierarchical Control', reprinted in H. H. Pattee and J. Rączaszek-Leonardi (eds), Laws, Language and Life, Dordrecht: Springer, pp. 91-110, [2012].

Pattee, H. H. [1982]: 'Cell Psychology: An Evolutionary Approach to the Symbol-Matter Problem', reprinted in H. H. Pattee \& J. Rączaszek-Leonardi (eds), Laws, Language and Life, Dordrecht: Springer, pp. 165-79, [2012].

Polányi, M. [1958]: Personal Knowledge: Towards a Post-Critical Philosophy, New York: Harper Torchbooks.

Ross, D., Ladyman, J. and Collier, J. [2007]: 'Rainforest Realism and the Unity of Science', in J. Ladyman and D. Ross, Every Thing Must Go: Metaphysics Naturalized, Oxford: Oxford University Press, pp. 190-257.

Ross, D., Ladyman, J. and Spurrett, D. [2007]: 'Causation in a Structural World', in J. Ladyman and D. Ross, Every Thing Must Go: Metaphysics Naturalized, Oxford: Oxford University Press, pp. 258-97.

Salmon, W. [1984]: Scientific Explanation and the Causal Structure of the World, Princeton, NJ: Princeton University Press.

Shoemaker, S. [1998]: 'Causal and Physical Necessity', Pacific Philosophical Quarterly, 79, pp. 59-77.

Smart, J. J. C. [1963]: Philosophy and Scientific Realism, London: Routledge and Kegan Paul.

Stein, D. L. (ed.) [1989]: Lectures in the Sciences of Complexity, Redwood City, CA: AddisonWesley.

Taylor, J. R. [2005]: Classical Mechanics, Sausalito, CA: University Science Books.

Weissman, D. [1965]: Dispositional Properties, Carbondale: Southern Illinois University Press.

Wimsatt, W. C. [1976]: 'Reductive Explanation: A Functional Account', Proceedings of the Biennial Meeting of the Philosophy of Science Association, 1974, pp. 671-710.

Wimsatt, W. C. [1994]: 'The Ontology of Complex Systems: Levels of Organization, Perspectives, and Causal Thickets', Canadian Journal of Philosophy, Suppl. Vol. 20, pp. 207-74.

Wimsatt, W. C. [2007]: Re-Engineering Philosophy for Limited Beings: Piecewise Approximations to Reality, Cambridge, MA: Harvard University Press. 
Winning, J. and Bechtel, W. [forthcoming]: 'Rethinking Causality in Biological and Neural Mechanisms: Constraints and Control', Minds and Machines, $<$ https://doi.org/10.1007/s11023-018-9458-5>.

Woodward, J. [2003]: Making Things Happen: A Theory of Causal Explanation, Oxford: Oxford University Press.

Woodward, J. [2008]: 'Response to Strevens', Philosophy and Phenomenal Research, 77(1), pp. $193-212$. 